\title{
The relationship of human milk leptin and macronutrients with gastric emptying in term breastfed infants
}

\author{
Anna M. Cannon ${ }^{1,3}$, Zoya Gridneva ${ }^{1,3}$, Anna R. Hepworth ${ }^{1}$, Ching T. Lai ${ }^{1}$, Wan J. Tie ${ }^{1}$, Sadaf Khan ${ }^{2}$, Peter E. Hartmann ${ }^{1}$ and \\ Donna T. Geddes ${ }^{1}$
}

BACKGROUND: Infants breastfed on demand exhibit a variety of feeding patterns and self-regulate their nutrient intake, but factors influencing their gastric emptying (GE) are poorly understood. Despite research into appetite regulation properties of leptin, there is limited information about relationships between human milk leptin and infant GE.

METHODS: Gastric volumes were calculated from ultrasound scans of infants' stomachs $(n=20)$ taken before and after breastfeeding, and then every $12.5 \mathrm{~min}$ (median; range: 3-45 min) until the next feed. Skim milk leptin and macronutrient concentrations were measured and doses were calculated.

RESULTS: The leptin concentration was (mean \pm SD) $0.51 \pm 0.16 \mathrm{ng} / \mathrm{ml}$; the leptin dose was $45.5 \pm 20.5 \mathrm{ng}$ per feed. No relationships between both concentration and dose of leptin and time between the feeds $(P=0.57 ; P=1$, respectively) or residual stomach volumes before the subsequent feed $(P=0.20 ; \quad P=0.050)$ were found. Post-feed stomach volumes (GE rate) were not associated with leptin concentration $(P=0.77)$ or dose $(P=0.85)$.

CONCLUSION: GE in term breastfed infants was not associated with either skim milk leptin concentration or dose. Further investigation with inclusion of whole-milk leptin and other hormones that affect gastrointestinal activity is warranted.

T he early programming of infant appetite is a complex concept that needs further research, to fully understand how infant feeding behavior contributes to the development of obesity and other chronic noncommunicable diseases, the incidence of which is markedly rising (1). Infants breastfed on demand are known to self-regulate their nutrient intake (2) and to develop better appetite control when introduced to solid food as opposed to their formula-fed counterparts $(3,4)$. It is assumed that these effects are partly mediated by the composition of human milk (HM), which contains appetite control factors, such as leptin, ghrelin, and adiponectin (3); however, gastric emptying (GE), a key regulator of appetite, (5) has been largely unexplored.

GE can be defined as the process in which food is emptied from the stomach into the small intestine for further digestion and absorption (5). In infants, patterns of GE vary depending on postnatal age and the type of milk they receive (artificial or HM). In preterm infants, the pattern changes from linear to curvilinear between 28 and 32 weeks of gestation as the gastrointestinal tract matures (6). Breastfed infants exhibit a curvilinear pattern, whereas formula-fed infants have a more linear pattern $(7,8)$. HM and formulas with different casein to whey ratios have also been shown to have different GE rates, with casein-dominant formulas emptying more slowly than whey-dominant formulas in term infants $<12$ months of age (9). This evidence suggests that differences in HM composition may influence GE rates, with the potential to influence feeding patterns and infant growth $(9,10)$.

Leptin is an appetite control hormone also present in HM; it has multiple functions and has been shown to modulate the gastrointestinal tract through the vagal afferent nerve (11). In murine model, central administration of leptin has been shown to inhibit GE of a glucose solution (12). In rat model, central administration of leptin slowed GE of a solid meal and intraperitoneal injections reduced food intake but did not affect gastric transit (13), and animals that received leptin orally during lactation period were better protected against fat accumulation and more sensitive to the short- and long-term regulation of food intake by leptin (14). Interestingly, cholecystokinin (CCK), a peptide hormone of the gastrointestinal system responsible for stimulating the digestion of fat and protein, appears to be involved in a feedback loop with leptin and is also involved in satiety. The effects of leptin have also been shown to differ depending on either the presence or absence of CCK. Leptin regulates feeding behavior and appetite in the absence of CCK and increases GI tract motility if CCK is present (11). Studies in murine models have confirmed that ingested maternal milk leptin is absorbed in the stomach and transferred to the circulation, remaining biologically active (15). However, although recent studies

\footnotetext{
${ }^{1}$ School of Molecular Sciences, The University of Western Australia, Perth, Australia; ${ }^{2}$ Department of Biochemistry (DIMC) and DOW Research Institute of Biotechnology and Biomedical Sciences, DOW University of Health Sciences, Karachi, Pakistan. Correspondence: Zoya Gridneva (zgridneva@gmail.com)

${ }^{3}$ The first two authors contributed equally to this work.

Received 24 August 2016; accepted 11 March 2017; advance online publication 24 May 2017. doi: 10.1038/pr.2017.79
} 
Table 1. Subject characteristics

\begin{tabular}{|c|c|c|c|}
\hline Characteristic & Mean \pm SD & Median (IQR) & Range \\
\hline Maternal age (years) & $31 \pm 4^{a}$ & $32(28,34)$ & $22-40$ \\
\hline Infant age (weeks) & $13 \pm 7$ & $10(8,18)$ & $6-32$ \\
\hline Pre-feed residual R1 (ml) & $7.5 \pm 14.8$ & $0.0(0.0,6.0)$ & $0.0-56.9$ \\
\hline Feed duration (min) & $26 \pm 13$ & $21(18,26)$ & $13-72$ \\
\hline Milk intake (ml) & $90 \pm 30$ & $92(70,124)$ & $36-140$ \\
\hline Time between feeds (min) & $64 \pm 33$ & $65(37,75)$ & $12-131$ \\
\hline Pre-feed residual R2 (ml) & $21.8 \pm 22.5$ & $14.5(2.6,32.2)$ & $0.0-87.2$ \\
\hline
\end{tabular}

Table 2. Skim milk leptin and macronutrient concentrations and doses

\begin{tabular}{|c|c|c|}
\hline Characteristic & Mean \pm SD & Range \\
\hline Skim milk leptin concentration $(\mathrm{ng} / \mathrm{ml})^{\mathrm{a}}$ & $0.51 \pm 0.16^{\mathrm{b}}$ & $0.42-1.15$ \\
\hline Protein concentration $\left(g / l^{c}\right.$ & $12.50 \pm 1.76$ & $9.60-15.36$ \\
\hline Lactose concentration $(\mathrm{g} / \mathrm{l})^{c}$ & $64.42 \pm 4.95$ & $53.23-75.32$ \\
\hline Fat concentration $(\mathrm{g} / \mathrm{l})^{\mathrm{d}}$ & $46.38 \pm 11.28$ & $26.59-65.23$ \\
\hline Skim milk leptin dose $(\mathrm{ng})^{\mathrm{a}}$ & $45.46 \pm 20.47$ & $17.88-108.51$ \\
\hline Protein dose $(g)^{c}$ & $1.13 \pm 0.32$ & $0.52-1.69$ \\
\hline Lactose dose $(\mathrm{g})^{c}$ & $5.94 \pm 1.85$ & $2.67-9.44$ \\
\hline Fat dose $(\mathrm{g})^{\mathrm{d}}$ & $4.29 \pm 1.69$ & $1.87-8.09$ \\
\hline $\begin{array}{l}\text { a }(n=20) . \\
{ }^{b} \text { Data expressed as mean } \pm S D \text { and range. } \\
C(n=18) . \\
d(n=19) .\end{array}$ & & \\
\hline
\end{tabular}

confirm associations between both infant serum leptin and BMI and HM leptin (16), or infant weight and HM leptin (17), it is not well understood either to what extent GE acts as an appetite regulator or how leptin affects infant GE.

$\mathrm{HM}$ is both a unique and dynamic fluid with superior composition, the components of which vary between feeds within women and between women (18-20). When infants breastfeed on demand and thereby control their nutrient intake (2), it is plausible that their GE pattern could be influenced by milk composition. Indeed, it has been shown that the frequency of breastfeeding is reduced with increased total 24-h protein intake, and is increased with increased lactose concentration (19). This suggests that variations in macronutrients, as well as appetite hormones such as leptin, may potentially influence GE patterns and at least partly explain the wide variation in feeding patterns displayed by breastfed infants $(2,19)$.

This study investigated the relationship of skim milk leptin and the macronutrients protein, lactose, and fat of HM with GE in term breastfed infants.

\section{RESULTS}

\section{Subjects}

Characteristics of the participants are described in Table 1. At the study session, infants fed from one $(n=16)$ or both

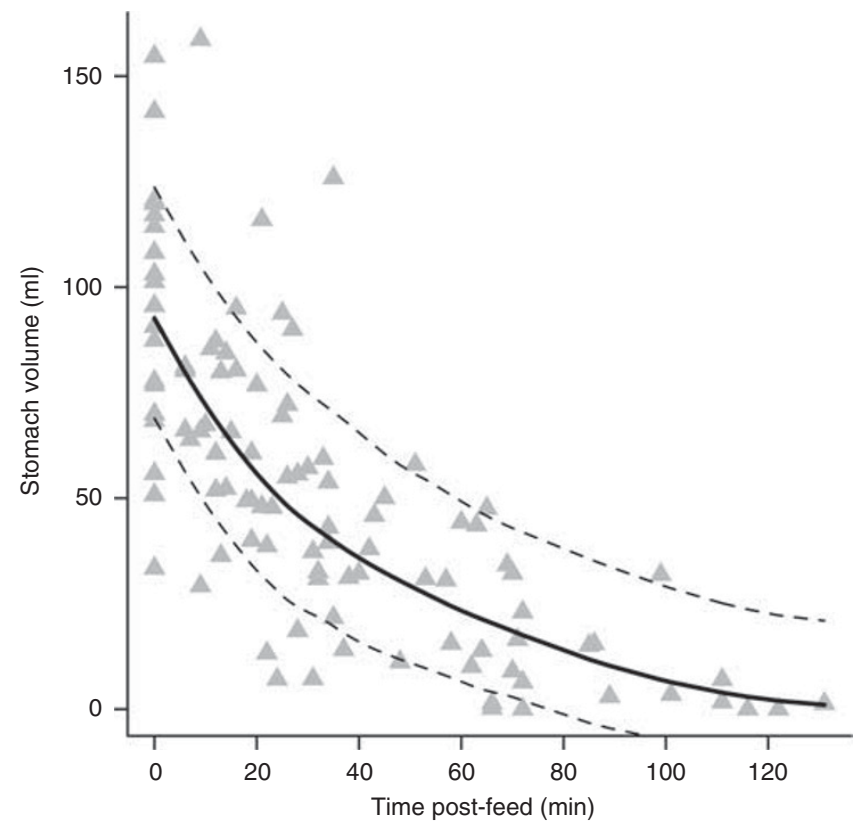

Figure 1. Overall curvilinear pattern of infant gastric emptying of human milk. Data points represent stomach volumes between two feeds calculated by ultrasound imaging. The lines represent changes in stomach volume as measured by ultrasound imaging. Bold line represents local regression smoother (LOESS). Dotted lines represent \pm SDs.

$(n=4)$ breasts and cued for the first feed (F1) with different stomach residual volumes (R1) (Table 1).

\section{HM Components}

Leptin and macronutrient concentrations and doses per feed are presented in Table 2. Protein and lactose measurements are missing for two participants, and fat measurements are missing for one participant.

\section{GE Rate}

The overall pattern and the individual GE curves are shown in Figures 1 and 2, respectively. The stomach volumes measured immediately after feed were positively associated with milk intake $(0.73(0.33,1.13), P=0.003)$. After accounting for the time post feed at each of the measurement time points $(P<0.001)$, milk intake was positively associated with all calculated post-feed stomach volumes $(P=0.001)$; each additional millilitresof feed resulted in $0.37(0.17,0.57) \mathrm{ml}$ greater stomach volume.

After accounting for time post feed $(P<0.001)$ and the milk intake $(P<0.003)$, no associations were seen between the measured milk components and the post-feed stomach volumes (Table 3 ).

\section{Milk Components and Feed Variables}

Time between feeds was not associated with milk intake $(0.19$ $(-0.33,0.71), P=0.48)$. 


\section{Articles | Cannon et al.}
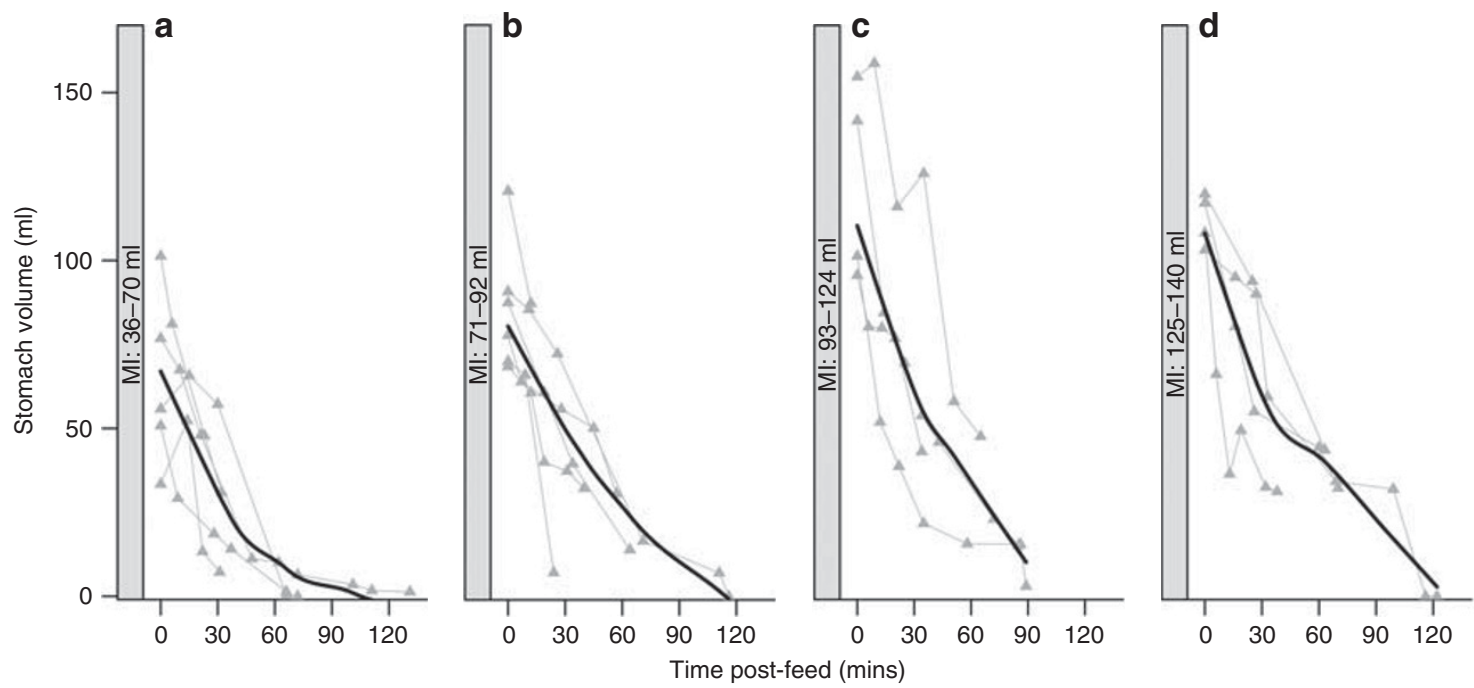

Figure 2. Gastric emptying of individual feeds in term breastfed infants ( $n=20$ feeds). Feeds are grouped by the milk intake (MI)—(a) 36-70 ml, (b) 71-92 ml, (c) 93-124 ml, and (d) 125-140 ml-to illustrate how larger feed volumes empty slower; approximately equal numbers are included in each panel. Data points represent stomach volumes calculated from ultrasound images; connecting gray lines link measurements from the same feed. Bold black line represents local regression smoother (LOESS, span $=0.9)$.

Table 3. Human milk components and pattern of post-feed stomach volumes (GE rate)

\begin{tabular}{|c|c|c|c|}
\hline Components & Estimate $\pm \mathrm{SE}$ & $(95 \% \mathrm{Cl})$ & $P$-value \\
\hline \multicolumn{4}{|l|}{ Concentrations } \\
\hline Leptin $(\mathrm{ng} / \mathrm{ml})^{\mathrm{a}}$ & $7.92 \pm 27.06^{b}$ & $(-49.18,65.02)$ & 0.77 \\
\hline Protein $(\mathrm{g} / \mathrm{l})^{c}$ & $-0.20 \pm 2.78$ & $(-6.12,5.72)$ & 0.94 \\
\hline Lactose $(\mathrm{g} / \mathrm{l})^{c}$ & $-0.23 \pm 0.61$ & $(-1.52,1.06)$ & 0.71 \\
\hline Fat $(g / l)^{d}$ & $0.03 \pm 0.26$ & $(-0.53,0.58)$ & 0.93 \\
\hline \multicolumn{4}{|l|}{ Doses } \\
\hline Leptin $(n g)^{a}$ & $0.06 \pm 0.29$ & $(-0.56,0.67)$ & 0.85 \\
\hline Protein $(\mathrm{g})^{c}$ & $6.12 \pm 31.09$ & $(-60.13,72.38)$ & 0.85 \\
\hline Lactose $(g)^{c}$ & $-2.53 \pm 6.33$ & $(-16.01,10.95)$ & 0.70 \\
\hline Fat $(g)^{d}$ & $0.82 \pm 2.46$ & $(-4.39,6.02)$ & 0.74 \\
\hline \multicolumn{4}{|c|}{$\begin{array}{l}\text { a }(n=20) \text {. } \\
\text { bData expressed as parameter estimate } \pm \text { SE and } 95 \% \mathrm{Cl} \text { after accounting for the } \\
\text { time effect and the feed volume, } n=20 \text { feeds. } \\
{ }^{c}(n=18) \text {. } \\
{ }^{d}(n=19) \text {. }\end{array}$} \\
\hline
\end{tabular}

No associations were found between measured milk components and any of the considered feed variables (Table 4).

\section{Milk Intake and Pre-Feed Residuals}

There was no association between milk intake and R1 $(-0.86$ $(-1.79,0.06), P=0.079)$, or stomach volumes measured immediately post feed and R1 $(0.54(-0.42,1.49, P=0.28)$.

No relationship was seen between R2 and milk intake $(0.24$ $(-0.04,0.53), P=0.10)$ in the univariate model, but after accounting for time post feed $(-0.35(-0.55,-0.15)$, $P=0.005)$ R2 was positively associated with milk intake (0.29 (0.007, 0.51), $P=0.015)$.

\section{Demographics and GE Parameters}

After accounting for time post feed $(P<0.001)$ and the milk intake $(P<0.002)$, no associations were seen between the post-feed stomach volumes and infant sex $(-1.75(-16.36$, $12.85), P=0.80)$, infant age $(0.76(-0.09,1.61), P=0.076)$, or maternal age $(-1.09(-2.69,0.52), P=0.17)$.

Milk intake was not associated with infant sex (18.01 $(-11.04,47.06), P=0.24)$, infant age $(-0.62(-2.68,1.44)$, $P=0.58)$, or maternal age $(2.28(-0.90,5.46), P=0.17)$.

$\mathrm{R} 1$ and R2 were not associated with infant sex $(-0.52$ $(-3.77,2.73), \quad P=0.75 ; 13.00 \quad(-6.66,32.66), \quad P=0.22$, respectively), infant age $(0.15(-0.05,0.35), P=0.27 ; 0.38$ $(-0.91,1.67), P=0.57$, respectively), or maternal age $(-0.10$ $(-0.47, \quad 0.27), \quad P=0.57 ; \quad 0.32 \quad(-1.95, \quad 2.59), \quad P=0.78$, respectively).

Time between feeds was not associated with infant sex $(-23.41(-53.50,6.68), P=0.15)$, infant age $(-0.07(-2.21$, $2.07), P=0.95)$, or maternal age $(-2.61(-6.08,0.86)$, $P=0.16)$.

\section{DISCUSSION}

On the basis of the hypothesis that the HM composition influences GE $(9,10)$ in term infants, we expected low concentrations and/or doses of the HM hormone leptin to be associated with increased GE. However, using ultrasound imaging, which we showed to be an accurate measure of milk intake, neither leptin concentration nor leptin dose was related to GE rate or the time between feeds. Further, while some evidence suggests $(2,19)$ that macronutrients in HM are associated with feeding patterns, these were not associated with either GE rate or time between feeds in this study. The only factor related to GE was the volume of milk consumed by the infant. 


\section{Human milk leptin and gastric emptying Articles}

Table 4. Effects of measured milk components (concentrations and doses) on feed variables

\begin{tabular}{|c|c|c|c|c|c|c|}
\hline \multirow[t]{2}{*}{ Components } & \multicolumn{2}{|l|}{ Milk intake } & \multicolumn{2}{|l|}{ Time between feeds } & \multicolumn{2}{|l|}{ Residual R2 } \\
\hline & Estimate $\pm \mathrm{SE}(95 \% \mathrm{Cl})$ & $P$-value & Estimate $\pm \mathrm{SE}(95 \% \mathrm{Cl})$ & $P$-value & Estimate $\pm \mathrm{SE}(95 \% \mathrm{Cl})$ & $P$-value \\
\hline \multicolumn{7}{|l|}{ Concentrations } \\
\hline Skim milk leptin $(\mathrm{ng} / \mathrm{ml})^{\mathrm{b}}$ & $\begin{array}{l}-0.80 \pm 47.70^{\mathrm{a}} \\
(-94.30,92.71)\end{array}$ & 0.99 & $\begin{array}{c}-28.12 \pm 51.07 \\
(-128.21,71.97)\end{array}$ & 0.57 & $\begin{array}{c}-156.62 \pm 28.76 \\
(-212.99,-100.24)\end{array}$ & 0.20 \\
\hline Protein $(\mathrm{g} / \mathrm{l})^{\mathrm{d}}$ & $-6.93 \pm 3.87(-14.51,0.65)$ & 0.09 & $-5.72 \pm 4.94(-15.39,3.96)$ & 0.26 & $-0.10 \pm 2.99(-5.97,5.77)$ & 0.97 \\
\hline Lactose $(\mathrm{g} / \mathrm{l})^{\mathrm{d}}$ & $-1.10 \pm 1.53(-4.10,1.91)$ & 0.48 & $-1.04 \pm 1.83(-4.62,2.54)$ & 0.57 & $-0.46 \pm 1.06(-2.53,1.62)$ & 0.66 \\
\hline Fat $(g / l)^{c}$ & $0.02 \pm 0.65(-1.25,1.29)$ & 0.97 & $-0.79 \pm 0.75(-2.27,0.68)$ & 0.31 & $0.26 \pm 0.48(-0.68,1.21)$ & 0.60 \\
\hline
\end{tabular}

\begin{tabular}{|c|c|}
\hline \\
\hline Skim milk leptin $(\mathrm{ng})^{\mathrm{b}}$ & $N / A^{e}$ \\
\hline Protein $(\mathrm{g})^{\mathrm{d}}$ & $\mathrm{N} / \mathrm{A}$ \\
\hline Lactose $(g)^{d}$ & $\mathrm{~N} / \mathrm{A}$ \\
\hline Fat $(g)^{c}$ & $\mathrm{~N} / \mathrm{A}$ \\
\hline \multicolumn{2}{|c|}{$\begin{array}{l}\text { N/A, not available. } \\
{ }^{2} \text { Data expressed as parameter estimate } \pm \text { SE and } 95 \% \mathrm{Cl} \text {. } \\
b^{2}(n=20) . \\
{ }^{c}(n=19) \text {. } \\
d^{(}(n=18) \text {. } \\
{ }^{2} \text { Dose was not tested as it was derived from milk intake }\end{array}$} \\
\hline
\end{tabular}

This study failed to show a relationship between skim milk leptin concentration and dose of leptin delivered at a breastfeed and the rate of GE or the time between the feeds. This agrees with our previous study, which did not find an association between skim milk leptin dose and the time between the feeds across a 24-h period (20). Milk leptin has been shown to be biologically active and enter the circulation (15), whereby satiety may be affected via signaling to the hypothalamus to reduce food intake (21). GE is another pathway by which leptin may regulate patterns of feeding. Leptin and its receptor have been initially detected in the gastric mucosa of adult humans (22) and animals (23), and then later it was found that all mucosae in human fetus start expressing the leptin $\mathrm{Ob}-\mathrm{Rb}$ receptor between the seventh and ninth week of gestation, and leptin protein around the 11th week, suggesting an important role of leptin in the developmental process of the human digestive tract (24). Gastric leptin can be secreted into the infant gastric lumen in response to HM, which also contains leptin. Thus, the absence of associations between HM leptin and infant GE parameters could be a result of multiple factors, such as the inability to measure the intragastric leptin released in response to a feed, measurement of leptin in skim milk rather than whole milk, and the interaction with other appetite hormones such as ghrelin. The greatest activation of ghrelin receptors has been identified in the stomach rather than the hypothalamus, as previously assumed, suggesting an important role for ghrelin in the regulation of GE (25). Scientific investigation is yet to refine our understanding of the intricacies of gastric function, particularly in relation to bioactive molecules such as leptin, whose actions are influenced by CCK, and ghrelin in HM.

Leptin is known to have multiple roles in the metabolism and rapid growth of the newborn infant, including developing areas of the hypothalamus that control and regulate energy balance (26), influencing motility of the small intestine and modulating intestinal inflammatory response, and potentially controlling the assimilation of macronutrients, fats, and proteins (11). Most studies that have investigated associations between macronutrient concentrations and GE were conducted on bovine-based formula milk, for which the structure of molecules differs from HM. These studies show that high levels of fat, protein, and carbohydrate content, as well as high energy and high osmolality of formula, are associated with slower GE $(27,28)$. In terms of macronutrients, we did not find any relationship between the concentrations and doses of fat, protein, or lactose of the ingested HM and GE rate or time between the feeds, suggesting differences in the actions of these HM components compared with bovine-based formulas. Although one of our previous studies has shown that the increased concentrations of lactose was associated with feeding frequency over a 24-h period (19), this does not directly relate to the time between feeds (a proxy measure of GE), which is highly variable in most infants and also could be influenced by breast storage capacity (2). Further work evaluating the effects of the actual protein composition of HM such as the casein and whey concentrations and the ratio of casein and whey on GE of infants may be valuable. Bovine and HM casein and whey differ in their digestion (9), and both whey and the ratio of casein and whey have been shown to influence GE in formula studies. In term infants, casein-dominant formulas have been shown to reduce GE, whereas both whey-dominant formulas and hydrolyzed casein increased GE $(9,29)$. Thus, the variable ratio of casein and whey demonstrated in HM (30) may partly explain differences in GE rates and the feeding frequency in term breastfed infants.

Another determinant of GE and appetite regulation is gastric distention (31). In rats, the volume of milk ingested 


\section{Articles | Cannon et al.}

affects the rate of GE, as well as suppression of the following feed volume (32). In preterm infants, delayed GE is regarded as a risk factor for feed intolerance and necrotizing enterocolitis (33), but there is no documented investigation of the influence of feed volume on GE rates in term infants. This study shows that HM empties in a curvilinear manner (Figure 2) and larger feed volumes result in larger post-feed stomach volumes, which is different from that of the preterm infant where feed volume has been documented to have no effect on GE rate (34).

Existing studies of the normal physiological emptying of the stomach in the term infant have used either ultrasound of the antral area and reported half-emptying times (7) or scintigraphy in children from 6 months to 3 years (8); our study differs from these as infants were allowed to feed on demand and were monitored for the entire period between feeds. It is a common assumption that an infant cuing for a feed is hungry and has an empty stomach (35). Using ultrasound, we measured the residual stomach volumes before feeding and found that 55\% (11/20) of infants cued for the first feed and $85 \%$ (17/20) of infants cued for the second feed with a detectable residual stomach volume, suggesting that it is common for breastfed infants to have HM in the stomach before feeding. Milk contains multiple components such as growth factors and antimicrobial peptides, which are likely involved in the development and protection of the gastrointestinal tract. Leptin itself is known to stimulate gut mucosal cell proliferation and inhibit apoptosis (11); therefore, it may be potentially detrimental to extend times between feeds, increasing the likelihood of an empty stomach devoid of HM components.

One limitation of this study was that it monitored one breastfeed, and therefore we were unable to determine whether the residual volume was related to the volume consumed at each feed-i.e., whether the infant topped up to the same volume at each feed, and the variability in feed volume was in fact related to the residual stomach volume. The sample size is not a limitation of the study, as although no associations between milk composition and GE rate were detected, we were able to clearly show a relationship between milk intake and GE rate (post-feed stomachs). Ideally, a longitudinal study with larger numbers of infants monitored over several feeds would allow for investigation of the effect of stomach residual volumes on milk intake, as well as the association with macronutrients and multiple appetite hormones (e.g., ghrelin, adiponectin) with GE in greater depth.

In conclusion, in term breastfed infants feed volume affects GE, whereas the GE rate and time between two consecutive feeds are not associated with HM concentrations or doses of skim milk leptin, total protein, lactose, and fat. More detailed investigation of multiple components of $\mathrm{HM}$, including whole-milk leptin, ghrelin, adiponectin, and casein and whey protein, in a larger cohort is required to gain a more comprehensive understanding of GE in term breastfed infants. In addition, multiple feeds could be monitored to determine the impact of final residual stomach volume on infant milk intake.

\section{METHODS}

\section{Subjects}

Breastfed infants $(n=20)$ of English-speaking (predominantly Caucasian) mothers of higher socioeconomic status from a developed country were recruited through the Australian Breastfeeding Association and community centers between 2012 and 2013. Inclusion criteria were healthy, term (37-40 weeks) singletons, fully breastfed on demand at the point of measurement. Exclusion criteria were infant health issues requiring medication that could potentially influence GE rate (e.g., reflux), infant factors that could potentially influence growth and development, maternal smoking, and low milk supply. Mothers were between 22 and 40 years of age, in good health, and were experiencing no lactation issues. All procedures were approved by The Human Research Ethics Office of The University of Western Australia (RA/1/4253), and the participants provided informed written consent to participate in the study.

\section{Design}

Study session. Participants visited our laboratory at King Edward Memorial Hospital for Women (Subiaco, Perth, WA, Australia) on one occasion to monitor the GE of one feed. Before the first feed (F1), infants were weighed and had ultrasound stomach volume measurements taken (pre-feed residual volume, R1). Mothers expressed a small sample of milk from the feeding breast/breasts and breastfed their infants as usual. Immediately after F1, infant stomach volumes were measured with ultrasound and infants were weighed again. Subsequent scans of the stomach were scheduled every 15-20 min intervals (median $12.5 \mathrm{~min}$; range: $3-45 \mathrm{~min}$ ) until the infant cued for the next feed (F2). Stomach volume immediately before F2 was measured (pre-feed residual volume, R2). Post-feed stomach volumes were measured $4.4 \pm 1.6$ times.

Milk sample collection. Mothers hand-expressed or pumped small (1-2 ml) milk samples into $5 \mathrm{ml}$ polypropylene plastic vials (Disposable Products, Adelaide, SA, Australia) before and after F1 from the feeding breast/breasts. Fat content was measured using the creamatocrit method (below) immediately after sample collection, after which samples were stored at $-20^{\circ} \mathrm{C}$ for further biochemical analysis.

Milk intake. The volume of milk consumed from a breast by the infant was determined by test weighing the infant immediately before and after the breastfeed using an electronic scale $( \pm 2 \mathrm{~g}$, BabyWeigh Scale, Medela, McHenry, IL, USA). Milk intake (g) was calculated by subtracting the initial weight from the final weight (36) and was converted to $\mathrm{ml}$.

Ultrasound measurements. The infants' stomach was measured using the Toshiba SSA-770A/80, Aplio 80 (Tokyo, Japan) ultrasound machine with a PVT-674BT $(6 \mathrm{MHz})$ transducer, and Parker ultrasonic gel (Fairfield, NJ, USA), with the infant in the semireclined position. The sagittal and transverse planes of the stomach were used to measure the longitudinal (L), anterior-posterior (AP), and transverse $(\mathrm{T})$ diameters directly from images on the ultrasound screen. All of the measurements were performed by one experienced sonographer (DG) with previously reported high intra-observer reliability of intraclass correlation coefficients (ICCs) $>0.99(95 \%$ confidence interval $(\mathrm{CI}))$. Stomach volume $(\mathrm{ml})$ was calculated with the following ellipsoidal formula using the above measured diameters (10):

$$
\text { Stomach volume }(\mathrm{ml})=L(\mathrm{~mm}) \times \mathrm{AP}(\mathrm{mm}) \times T(\mathrm{~mm}) \times 0.52
$$

Biochemical analysis. Immediately after the sample collection and before freezing the samples, fat concentration was determined by the creamatocrit method (37) using the Creamatocrit Plus device 
(Medela). Fat content of the milk samples was calculated from the cream content of the milk samples, using the following equation (38):

Fat content $(\mathrm{g} / \mathrm{l})=5.917 \times$ cream percentage +3.56

Before further analysis, all samples were thawed at room temperature and aliquots were prepared in $1.5 \mathrm{ml}$ tubes (Sarstedt, Numbrecht, Germany). Skim milk was prepared by centrifugation at room temperature in a Beckman Microfuge 11 (Aberdon Enterprise, Elk Grove Village, IL, USA) at 7,537g for $10 \mathrm{~min}$. The fat layer was removed by clipping it off together with the top of the tube.

All skim milk samples were analyzed for total protein, lactose, and leptin concentrations. Protein concentration was measured using the Bradford protein assay and lactose concentration was measured with the enzymatic-spectrophotometric method of Kuhn and Lowenstein (39), both adapted from Mitoulas et al. (18). Leptin concentration was measured using an enzyme-linked immunosorbent assay (ELISA) optimized to measure leptin in skim milk, as previously described (20).

Leptin and macronutrient dose. Doses were defined as the amount of leptin/macronutrient ingested during a breastfeed. The average of the pre- and post-feed leptin/protein/lactose/fat concentration was multiplied by the corresponding milk intake. When an infant fed from both breasts, the milk volumes were summed, as were the leptin/macronutrient doses.

\section{Statistical Analyses}

Statistical analysis was performed using $\mathrm{R}$ software package (version 2.9.0 for Mac OSX; R Foundation for Statistical Computing, Vienna, Austria) and additional packages MASS (robust regression), sfsmic (Wald tests for robust regression), and nlme (version 3.1-96, http:// CRAN.R-project.org/package $=$ nlme) $\quad$ (random effects models). Descriptive statistics are reported as mean $\pm S D$ and range, unless otherwise stated; model parameters are presented as estimate $\pm \mathrm{SE}$ and, where appropriate, an approximate $95 \%$ CI. $P$ values $<0.05$ were considered statistically significant.

Missing data included protein and lactose measurements for two participants, and fat measurements for one participant.

During this study, infants' post-feed stomach volumes were measured at $4.4 \pm 1.6$ time points. An approximate sample size was calculated using the 'Linear multiple regression: fixed model: r2 increase' option in $\mathrm{G}^{\star}$ Power (40) by assuming this to be a crosssectional study with equal numbers at each time. Allowing four predictors (one main effect and three time contrasts), $\alpha=0.05$, and 14 participants at each time point (56 sample points $=14$ participants $\times 4$ time points) gave the study power of 0.80 to detect an effect size of 0.15 . This approach was selected, as there is no closed-form expression suitable for the calculation of sample sizes for this research design. To maintain predicted power and to address issues relating to the missed measurements because of sleeping or unusually early feeding, the recruitment of participants continued past 14 .

Robust linear regression, using defaults specified by the MM-estimation method, was used to test for univariate associations between (a) milk component (leptin, protein, lactose, fat) concentrations and each of milk intake, time between feeds, and residual stomach volume before feed two (R2); (b) milk component doses and each of time between feeds and R2; (c) time between feeds and milk intake; and (d) maternal and infant demographic characteristics and milk intake, time between feeds, and R2. Approximate $P$ values were determined using the Wald test.

Post-feed stomach volumes were analyzed using linear mixedeffects models. Initial models considering only changes over time post feed were fitted using the fraction polynomial approach of Altman and Royston (41), with the chosen model having linear and inverse terms. Effects of milk composition and maternal/infant demographic characteristics on GE were then investigated by testing for associations between the post-feed stomach volumes and each of the milk component concentrations and doses after accounting for the post-feed time curve and the feed volume. Random intercept models were compared with random slope models. Random slopes were a significantly better fit to the data, except for protein concentration and protein dose, in which the models did not converge; random intercept models have been reported for these predictors.

\section{ACKNOWLEDGMENTS}

All authors read and approved the final manuscript. We like to thank all participants for their time and effort.

\section{STATEMENT OF FINANCIAL SUPPORT}

This study was supported by an Australian Postgraduate Award from The University of Western Australia (Australia; AC, ZG) and an unrestricted research grant from Medela AG (Switzerland; DG, PEH, AH, CTL, WJT). SK was supported by Higher Education Commission (Pakistan). Medela AG had no role in the design of the study; in the collection, analyses, or interpretation of the data; in the writing of the manuscript; and in the decision to publish the results.

Disclosure: The authors declare no conflict of interest.

\section{REFERENCES}

1. Geddes D, Prescott S. Developmental origins of health and disease: the role of human milk in preventing disease in the 21(st) century. J Hum Lact 2013;29:123-7.

2. Kent JC, Mitoulas LR, Cregan MD, Ramsay DT, Doherty DA, Hartmann PE. Volume and frequency of breastfeedings and fat content of breast milk throughout the day. Pediatrics 2006;117:e387-95.

3. Savino F, Liguori S, Fissore M, Oggero R. Breast milk hormones and their protective effect on obesity. Int J Pediatr Endocrinol 2009;2009:327505.

4. Hassiotou F, Geddes DT. Programming of appetite control during breastfeeding as a preventative strategy against the obesity epidemic. J Hum Lact 2014;30:136-42.

5. Hellstrom P, Gryback P, Jacobsson H. The physiology of gastric emptying. Best Pract Res Clin Anaesthesiol 2006;20:397-407.

6. Carlos M, Babyn P, Marcon M, Moore A. Changes in gastric emptying in early postnatal life. J Pediatr 1997;130:931-7.

7. Cavell B. Gastric emptying in infants fed human milk or infant formula. Acta Paediatr Scand 1981;70:639-41.

8. Gomez H, Hornoy P, Liehn J. Ultrasonography and gastric emptying in children: validation of a sonographic method and determination of physiological and pathological patterns. Pediatr Radiol 2003;33:522-9.

9. Meyer R, Foong R, Thapar N, Kritas S, Shah N. Systematic review of the impact of feed protein type and degree of hydrolysis on gastric emptying in children. BMC Gastroenterol 2015;15:137.

10. Perrella S, Hepworth A, Simmer K, Geddes D. Influences of breast milk composition on gastric emptying in preterm infants. J Paediatr Gastroenterol Nutr 2015;60:264-71.

11. Yarandi SS, Hebbar G, Sauer CG, Cole CR, Ziegler TR. Diverse roles of leptin in the gastrointestinal tract: modulation of motility, absorption, growth, and inflammation. Nutrition 2011;27:269-75.

12. Smedh U, Hakansson ML, Meister B, Uvnas-Moberg K. Leptin injected into the fourth ventricle inhibits gastric emptying. Neuroreport 1998;9: 297-301.

13. Martinez V, Barrachina M, Wang L, Tache Y. Intracerebroventricular leptin inhibits gastric emptying of a solid nutrient meal in rats. Neuroreport 1999;10:3217-21.

14. Pico C, Oliver P, Sanchez J, et al. The intake of physiological doses of leptin during lactation in rats prevents obesity in later life. Int J Obes 2007;31:1199-209.

15. Sanchez J, Oliver P, Miralles O, Ceresi E, Pico C, Palou A. Leptin orally supplied to neonate rats is directly uptaken by the immature stomach and may regulate short-term feeding. Endocrinology 2005;146: 2575-82. 


\section{Articles | Cannon et al.}

16. Savino F, Sardo A, Rossi L, Benetti S, Savino A, Silvestro L. Mother and infant body mass index, breast milk leptin and their serum leptin values. Nutrients 2016;8:383.

17. Brunner S, Schmid D, Zang K, et al. Breast milk leptin and adiponectin in relation to infant body composition up to 2 years. Pediatr Obes 2014;10: $67-73$.

18. Mitoulas LR, Kent JC, Cox DB, Owens RA, Sherriff JL, Hartmann PE. Variation in fat, lactose and protein in human milk over $24 \mathrm{~h}$ and throughout the first year of lactation. Br J Nutr 2002;88: 29-37.

19. Khan S, Hepworth AR, Prime DK, Lai CT, Trengove NJ, Hartmann PE. Variation in fat, lactose, and protein composition in breast milk over 24 Hours: associations with infant feeding patterns. J Hum Lact 2013;29: 81-9.

20. Cannon A, Kakulas F, Hepworth A, Lai C, Hartmann P, Geddes D. The effects of leptin on breastfeeding behaviour. Int J Environ Res Public Health 2015;12:12340-55.

21. Schwartz MW, Morton GJ. Obesity: keeping hunger at bay. Nature 2002;418:595-7.

22. Sobhani I, Bado A, Vissuzaine C, et al. Leptin secretion and leptin receptor in the human stomach. Gut 2000;47:178-83.

23. Goiot H, Attoub S, Kermorgant S, et al. Antral mucosa expresses functional leptin receptors coupled to STAT-3 signaling, which is involved in the control of gastric secretions in the rat. Gastroenterology 2001;121:1417-27.

24. Aparicio T, Kermorgant S, Darmoul D, et al. Leptin and Ob-Rb receptor isoform in the human digestive tract during fetal development. J Clin Endocrinol Metab 2005;90:6177-84.

25. Inui A, Asakawa A, Bowers CY, et al. Ghrelin, appetite, and gastric motility: the emerging role of the stomach as an endocrine organ. FASEB J 2004;18:439-56.

26. Stocker CJ, Cawthome MA. The influence of leptin on early life programming of obesity. Trends Biotechnol 2008;26:545-51.

27. Seigel M, Krantz B, Lebenthal E. Effect of fat and carbohydrate composition on the gastric emptying of isocaloric feedings in premature infants. Gastroenterology 1985;89:785-90.
28. Salvia G, De Vizia B, Manguso F, et al. Effect of intragastric volume and osmolality on mechanisms of gastroesophageal reflux in children with gastroesophageal reflux disease. Am J Gastroenterol 2001;96:1725-32.

29. Ferranti P, Traisci MV, Picariello G, et al. Casein proteolysis in human milk: tracing the pattern of casein breakdown and the formation of potential bioactive peptides. J Dairy Res 2004;71:74-87.

30. Kunz C, Lonnerdal B. Re-evaluation of the whey protein/casein ratio of human milk. Acta Pediatr 1992;81:107-12.

31. Hellstrom P, Naslund E. Interactions between gastric emptying and satiety, with special reference to glucagon-like peptide-1. Physiol Behav 2001;74:735-41.

32. Lorenz DN. Gastric emptying of milk in rat pups. Am J Physiol 1985;248: R732-8.

33. Moore TA, Wilson ME. Feeding intolerance: a concept analysis. Adv Neonatal Care 2011;11:149-54.

34. Ramirez Wong WW, Shulman RJ. Factors regulating gastric emptying in preterm infants. J Pediatr 2006;149:475-9.

35. Lawrence RA, Lawrence RM. Practical management of the mother-infant nursing couple. In: Lawrence RA, Lawrence RM, eds. Breastfeeding: A guide for medical profession, 7th edn. Maryland Heights, Missouri, USA: Mosby/Elsevier, 2011:232-283.

36. Arthur P, Hartmann P, Smith M. Measurement of the milk intake of breast-fed infants. J Pediatr Gastroenterol Nutr 1987;6:758-63.

37. Fleet I, Linzell J. A rapid method of estimating fat in very small quantities of milk. J Physiol 1964;175:15-7.

38. Meier P, Engstrom J, Zuleger J, et al. Accuracy of a user-friendly centrifuge for measuring creamatocrits on mothers' milk in the clinical setting. Breastfeed Med 2006;1:79-87.

39. Kuhn N, Lowenstein J. Lactogenesis in the rat. Changes in metabolic parameters at parturition. Biochem J 1967;105:995-1002.

40. Faul F, Erdfelder E, Buchner A, Lang A-G. Statistical power analyses using $G^{*}$ Power 3.1: tests for correlation and regression analyses. Behav Res Methods 2009;41:1149-60.

41. Royston P, Altman DG. Regression using fractional polynomials of continuous covariates: Parsimonious parametric modelling. Appl Stat-J Roy St C 1994;43:429-67. 